\title{
O RECONHECIMENTO DA SOCIOAFETIVIDADE NAS FAMÍLIAS RECOMPOSTAS: Uma Situação Fática ou Exercício da Autonomia Privada? ${ }^{1}$
}

\author{
http://dx.doi.org/10.21527/2176-6622.2020.54.288-299
}

Recebido em: 3/3/2020

Modificações solicitadas em: 20/4/2020

Aceito em: 21/7/2020

Luciane Sobral

Doutoranda e Mestra em Direitos Fundamentais e Democracia pelo Centro Universitário Autônomo do Brasil - UniBrasil. Especialista em Direito das Famílias e Sucessões pela Academia Brasileira de Direito Constitucional. Especialista em Direito Imobiliário Aplicado pela Escola Paulista de Direito. Bolsista Capes/Prosup. Pesquisadora do Núcleo de Pesquisa em Direito Constitucional do UniBrasil (Nupeconst) e do Núcleo de Pesquisa Direito Civil-Constitucional da UFPR (Grupo Virada de Copérnico). http://lattes.cnpq.br/4717961476039165. http://orcid. org/0000-0001-6863-2053. lucianesobral.adv@gmail.com

Marco Antonio Lima Berberi

Mestre e doutor em Direito pela UFPR. Professor na Graduação e no PPGD em Direito do Centro Universitário Autônomo do Brasil - UniBrasil. Pesquisador do Núcleo de Pesquisa em Direito Civil-Constitucional da UFPR (Grupo Virada de Copérnico) para o biênio 2018-2020. http://lattes.cnpq.br/6394664083768370. http://orcid. org/0000-0002-5132-6452. marcoberberi@gmail.com

\section{RESUMO}

O presente artigo visa a analisar a necessidade da autonomia privada no reconhecimento da socioafetividade em famílias recompostas. Utilizando-se do método hipotético-dedutivo, estabeleceu-se três hipóteses relacionadas à constituição da família recomposta e a relação entre padrastos, madrastas e enteados, no sentido de verificar a necessidade da manifestação de vontade das partes para o reconhecimento da filiação socioafetiva dentro desse modelo de família. A metodologia utilizada foi a análise doutrinária, legislativa e jurisprudencial. Dentre os resultados alcançados, destaca-se a compreensão das famílias recompostas em suas mais diversas formas de existência, bem como da socioafetividade e seus requisitos e, por fim, a eleição de uma das hipóteses como a correta para responder à problemática do presente estudo.

Palavras-chave: Socioafetividade. Famílias recompostas. Autonomia privada.

\section{THE RECOGNITION OF SOCIOAFFECTIVITY IN RECOMPOSED FAMILIES: A FACTICAL SITUATION OR EXERCISE OF PRIVATE AUTONOMY?}

\section{ABSTRACT}

This article aims to analyze the necessity of private autonomy in the recognition of socialaffectivity in recomposed families. Using the hypothetical-deductive method, three hypotheses have been established related to the constitution of the recomposed families and the relationships between stepparents and their stepchildren in order to verify the need for manifesting the will of the parties for the recognition of socialaffective affiliation within this model of family. The methodology used was doctrinal, legislative and jurisprudence analysis. The most significant results achieved were the understanding of recomposed families in their most diverse forms of existence, as well as the socialaffectivity and its requirements, and finally, the choice of one of the hypotheses as the correct one to answer the problematic of the present study.

Keywords: Socialaffectivity. Recomposed families. Private autonomy.

\section{SUMÁRIO}

1 Introdução. 2 A socioafetividade e as famílias recompostas. 2.10 reconhecimento da socioafetividade e os provimentos do CNJ que possibilitaram seu reconhecimento voluntário. 2.2 As famílias recompostas. 3 Os requisitos para o reconhecimento da socioafetividade. 4 Autonomia privada para o reconhecimento da socioafetividade nas famílias recompostas. 5 Considerações finais. 6 . Referências.

\footnotetext{
$\overline{1}$ O presente trabalho foi realizado com o apoio da Coordenação de Aperfeiçoamento de Pessoal de Nível Superior - Brasil (Capes) - Código de Financiamento 001
} 


\section{INTRODUÇÃO}

O tema socioafetividade possui amplo reconhecimento na sociedade atual. O ditado "pai é quem cria", utilizado antigamente como um incentivo àquele que criava filho gerado por outro, está muito mais consolidado, com menos preconceito e maior abrangência. Isto porque, ainda que de maneira tímida, nos dias atuais há casos em que o pai reside com o filho e a madrasta exerce o papel de mãe, de modo que o referido ditado precisa de adaptação para as novas realidades familiares.

É visível a evolução do conceito de família por meio das várias modalidades de entidades familiares existentes. Dentre elas, merece destaque, neste estudo, a denominada família recomposta, caracterizada pela presença de membros de relacionamentos anteriores, ou seja, cônjuges ou companheiros que, ao se unirem, já têm filhos, trazendo-os para o mesmo lar conjugal e podem ainda decidir por gerar ou adotar filhos em comum.

Ocorre que, na mesma intensidade em que houve mudanças nas formações das famílias, não se pode afirmar que exista um padrão a ser seguido por elas, de modo que cada lar familiar tem determinada forma de conviver e relacionar-se. Em virtude desta diversidade, é necessário analisar a socioafetividade e compreender se a mera convivência entre os membros permitiria o reconhecimento de maternidade ou paternidade socioafetiva; ou se, para que este instituto seja reconhecido, haveria necessidade de manifestação da autonomia de vontade dos indivíduos que se relacionam nesse ambiente familiar.

Neste sentido, pretende-se, inicialmente, abordar a socioafetividade, suas características e requisitos, passando pelas noções de famílias recompostas e de autonomia privada, para, então, responder à problemática estabelecida, utilizando-se o método hipotético-dedutivo e mediante a análise doutrinária, legislativa e jurisprudencial. O principal objetivo deste escrito é compreender a relação do padrasto e/ou madrasta e seus enteados, a fim de concluir se todas as famílias com essa formação constituem efetivamente filiações socioafetivas independente da vontade dos membros.

\section{A SOCIOAFETIVIDADE E AS FAMÍLIAS RECOMPOSTAS}

A socioafetividade não é figura recente em nossa sociedade. Nas palavras de Rodrigo da Cunha Pereira, redigidas na apresentação do livro de Christiano Cassetari, "José não era pai biológico de Jesus e no entanto o teve como seu verdadeiro filho" (PEREIRA apud CASSETARI, 2015, p. xv²); em outros termos, ainda que não conhecida por este termo, a socioafetividade já existia nos tempos de Cristo, e, segundo o fato histórico relembrado pelo referido autor, o próprio Jesus foi filho socioafetivo de José.

A discussão acerca da necessidade de desvinculação da paternidade da questão biológica é tema de artigo científico de elevada relevância redigido em 1979 e que permanece atual e pertinente, uma vez que este assunto vem sendo objeto de reflexões desde muito antes da definição da nomenclatura "socioafetividade" em nosso ordenamento jurídico:

Qual seria, pois, esse quid específico que faz de alguém um pai, independentemente da geração biológica?

Se se prestar atenta escuta às pulsações mais profundas da longa tradição cultural da humanidade, não será difícil identificar uma persistente intuição que associa a paternidade antes como o serviço que com a procriação. Ou seja: ser pai ou ser mãe não está tanto no fato de gerar quanto na circunstácia [sic] de amar e servir (VILLELA, 1979).

João Baptista Villela, já no final da década de 70 do século 20, defendia a "desbiologização da paternidade" - que inclusive fora o título de seu artigo -, ou seja, retirar o vínculo da procriação com o reconhecimento da paternidade. Com o passar dos anos esse entendimento evoluiu até chegar-se ao termo socioafetividade.

Para que seja reconhecida a socioafetividade, como o próprio nome faz referência, é imprescindível a existência de laços afetivos.

\footnotetext{
A página é citada em algarismos romanos por ser fiel referência à página da obra, uma vez que se trata da apresentação do livro de Christiano Cassetari redigida por Rodrigo da Cunha Pereira.
} 
O sangue e o afeto são razões autônomas de justificação para o momento constitutivo da família, mas o perfil consensual e a affecto constante e espontânea exercem cada vez mais o papel de denominador comum de qualquer núcleo familiar (PERLINGIERI, 2007, p. 244).

Segundo Ricardo Calderón (2013, p. 240-242), a afetividade passou a ser trabalhada no ordenamento jurídico a partir da Constituição de 1988, ainda que de forma implícita, posto que desde a hermenêutica civil-constitucional passou-se a perceber outro Direito de Família. Um dos exemplos da consolidação do afeto a partir da Constituição Federal é a igualdade entre os filhos, que acabou por elevar o elemento afetividade à relação paterno-filial.

\subsection{O Reconhecimento da Socioafetividade e os Provimentos do CNJ que Possibilitaram seu Reconhecimento Voluntário}

João Baptista Villela, Guilherme de Oliveira e Luiz Edson Fachin, foram pioneiros no estudo da afetividade no Direito Brasileiro. Com o passar do tempo, o tema ganhou interesse por parte de outros pesquisadores e os casos começaram a ser levados ao Judiciário. Com as decisões tomadas pelos julgadores para resolução de casos envolvendo a afetividade nas relações parentais, a socioafetividade alcançou relevância prática e notoriedade social.

Em 21 de agosto de 2007, o voto da relatora ministra Nancy Andrighi no Recurso Especial no 878.941/ DF mereceu reflexão, trazendo vários julgados do Superior Tribunal de Justiça - identificando a prevalência de decisões com base no vínculo biológico da filiação -, aos quais a ministra se manifestou contrária, conduzindo sua argumentação no sentido de que a socioafetividade não pode ser ignorada pelo Direito, conforme trecho de seu voto:

Assim como ocorreu na hipótese sub judice, a paternidade sócio-afetiva [sic] pode estar, hoje, presente em milhares de lares brasileiros. $O$ julgador não pode fechar os olhos a esta realidade que se impõe e o direito não deve deixar de lhe atribuir efeitos. [...] Paternidade sócio-afetiva [sic] e biológica são conceitos diversos e a ausência de uma não afasta a possibilidade de se reconhecer a outra. O reconhecimento da filiação sócio-afetiva [sic] pressupõe a ausência de vínculo biológico entre partes que constroem uma relação familiar e se reconhecem como pais e filhos (STF Resp 878.941/DF, 2007).

Analisando o referido julgamento no contexto em que fora inserido, e, diante da unânime manifestação dos demais ministros acompanhando o posicionamento da relatora, verifica-se que o referido acórdão apresenta-se como precedente judicial, isto é, uma decisão que serve de modelo para decisões posteriores (MACCORMICK apud PUGLIESE, 2017, p. 23).

Aqui, vale uma observação pertinente. Tem-se que o ordenamento jurídico brasileiro se filia ao sistema da Civil Law, em que a prática dos precedentes não é muito habitual e há prevalência de regras (em sua maioria objetivas) constantes na legislação. Ocorre que a figura dos precedentes não se vincula a decisões inovadoras, mas, sim, baseia-se na premissa de manutenção dos posicionamentos adotados em decisões já proferidas (PUGLIESE, 2017, p. 54), o que garante maior segurança jurídica e previsibilidade das Cortes.

Ainda que MacCormick questione que o Poder Judiciário assim agindo possa "criar o Direito" 3 - uma vez que as decisões judiciais são proferidas em parâmetros completamente diversos do processo legislativo parlamentar (MACCORMICK, 2008, p. 212) -, no caso em questão esta crítica não merece ser considerada porque a decisão judicial (leia-se, precedente) impulsionou a mudança de entendimento, e não necessariamente criou Direito (legislou-se), mas apenas um outro modo de pensar a questão.

No que se refere à afetividade e à pluralidade familiar, verifica-se que a intervenção do Judiciário auxiliou no desenvolvimento e notoriedade desses temas. Um exemplo é a decisão do STF, que, em 2011, permitiu o reconhecimento das uniões homoafetivas, ${ }^{4}$ enquanto os projetos de lei sobre o tema - que já estavam em andamento desde antes da decisão -, permanecem até o momento estagnados.

\footnotetext{
3 Apesar da crítica do autor corresponder aos sistemas de Common Law e mistos, verifica-se que, embora no Brasil seja adotado o sistema Civil Law, há uma cultura de alterações significativas no Direito conduzidas pelo Poder Judiciário (especialmente na figura do Supremo Tribunal Federal), diante da demora do Legislativo em promulgar leis que acompanhem as transformações da sociedade.

4 Ação Direta de Inconstitucionalidade (ADI 4277/DF) e a Arguição de Descumprimento de Preceito Fundamental (ADPF 132/RJ). (STF 2011).
} 
O mesmo ocorreu com o tema da socioafetividade. Após o precedente do Superior Tribunal de Justiça, supramencionado, em setembro de 2016 o Supremo Tribunal Federal julgou o Recurso Extraordinário no $898.060 /$ SC, reconhecido com repercussão geral, em que discutiu a prevalência da paternidade biológica em relação à socioafetiva ou vice-versa, cuja tese fixada foi:

A paternidade socioafetiva, declarada ou não em registro público, não impede o reconhecimento do vínculo de filiação concomitante baseado na origem biológica, com todas as suas consequências patrimoniais e extrapatrimoniais (STF, RE 898.060/SC, D.J. 29/09/2016, Relatoria Ministro Luiz Fux).

Tal decisão (com repercussão geral) motivou o Pedido de Providências formulado pelo Instituto dos Advogados de São Paulo que, por sua vez, levou o Conselho Nacional de Justiça a editar, em novembro de 2017, o Provimento 63/2017, que permitiu o reconhecimento voluntário da socioafetividade por meio de ato declaratório e pessoal realizado perante os oficiais de registro civil, além de instituir modelos específicos e únicos de certidão de nascimento, casamento e óbito.

Em 14 de agosto de 2019, o referido provimento foi alterado pelo provimento 83/2019 do CNJ; este incluiu o artigo 10-A no provimento anterior e versa exclusivamente sobre o reconhecimento da socioafetividade.

Dentre os requisitos e procedimentos do reconhecimento voluntário da socioafetividade previstos pelo provimento 63/2017 - dispostos do artigo 10 ao artigo 15 - estão: (i) a irrevogabilidade do reconhecimento voluntário da paternidade ou maternidade socioafetiva, posto que sua desconstituição poderá ser realizada apenas judicialmente em caso de vício de vontade, fraude ou simulação; (ii) a possibilidade de reconhecimento por pretenso pai ou mãe com mais de 18 anos, independente de estado civil, desde que haja diferença de idade de mais de 16 anos desse(a) em relação ao filho socioafetivo; e (iii) a vedação no reconhecimento da socioafetividade por irmãos ou ascendentes.

O procedimento de reconhecimento pode ser realizado em qualquer cartório de registro civil e não apenas no qual foi lavrado o assento de nascimento do filho, cabendo ao registrador a verificação dos documentos, identidade do requerente e coleta de termo próprio, com qualificação e assinatura.

O provimento 63/2017 previa a possibilidade de reconhecimento da filiação socioafetiva de pessoas de qualquer idade, constando apenas a necessidade de anuência do filho maior de 12 anos. O provimento $83 / 2019$ alterou esse dispositivo limitando a possibilidade de reconhecimento da filiação socioafetiva apenas aos maiores de 12 anos, e previu a exigibilidade de consentimento desses filhos.

A previsão de anuência pessoal dos pais perante o oficial de registro civil prevista no provimento 63/2017 foi mantida, bem como a previsão de que, na impossibilidade de manifestação dos pais ou do filho (quando obrigatório em razão da idade) ou na falta de um desses, a situação será apresentada ao juiz competente, e mantida, ainda, a previsão acerca da possibilidade de reconhecimento da maternidade ou paternidade socioafetiva por meio de documento público ou particular de última vontade, desde que presentes os trâmites do provimento.

Há também a previsão no provimento 63/2017 mantida pelo provimento posterior quanto às regras da tomada de decisão apoiada, caso envolva pessoa com deficiência, bem como há previsão quanto à necessidade de declaração pelo requerente de que não há discussão judicial quanto à filiação ou procedimento de adoção em relação ao filho que se pretende reconhecer socioafetivamente. O provimento 63/2017 traz expressa a informação de que o reconhecimento da socioafetividade não será obstáculo para a busca da verdade biológica judicialmente pelo filho reconhecido, e a referida disposição permanece sem alterações.

O reconhecimento da parentalidade somente poderá ser realizado de forma unilateral. O provimento 83/2019 esclarece que é permitida a inclusão de apenas um ascendente socioafetivo, ou seja, poderá ser incluído um pai socioafetivo ou uma mãe socioafetiva no registro de nascimento.

O provimento 83/2019 incluiu, ainda, a necessidade de verificação pelo registrador de elementos concretos que comprovem a existência de vínculo afetivo de paternidade ou maternidade socioafetiva, e traz a regulamentação de que, após a verificação dos requisitos para o reconhecimento da socioafetividade pelo registrador, este dependerá de parecer favorável do Ministério Público para realizar o registro.

Pois bem, analisados os provimentos que regulamentam o reconhecimento voluntário de paternidade ou maternidade socioafetiva, passa-se à análise das famílias recompostas. 


\subsection{As Famílias Recompostas}

Por família recomposta entende-se aquela formada a partir de um desmembramento de uma família constituída anteriormente: antes de existir uma família recomposta, existia, ao menos, uma família monoparental. ${ }^{5}$ Isto é, uma família formada por pais e filhos se dissolve, os filhos residem por um tempo com um dos pais (monoparentalidade), até que este inicie um novo relacionamento e opte por formar uma nova família. A esta nova família dá-se o nome de família recomposta ou reconstituída, formada pela presença de pai ou mãe com filhos de um relacionamento anterior, passando a existir a figura do padrasto ou madrasta, em um primeiro momento (VALADARES, 2005).

Padrastos e madrastas são nomenclaturas consideradas pejorativas em nossa sociedade, como bem lembra Maria Berenice Dias (1999). São representados, desde os contos de fadas, por pessoas cruéis, que não expressam sentimentos de amor e carinho pelos enteados. Por isso, é comum ouvir informalmente a readequação desta nomenclatura para "boadrasta", "mãedrasta" ou "paidrasto" etc., quando os enteados desejam referir-se com carinho ao (à) atual companheiro(a) de seu pai ou mãe.

A formação de famílias recompostas está cada vez mais comum, talvez em razão de, nos tempos atuais, as pessoas pouco se preocuparem com a família padrão, patriarcal e "quadrada". Ainda que seja comum, nem sempre os papéis assumidos pelos membros deste modelo de família são fáceis de serem administrados: "A dificuldade está na definição dos papéis de cada membro dessa entidade familiar e nos efeitos jurídicos decorrentes dos vínculos formados" (VALADARES, 2005).

Existem casos em que entre padrasto/madrasta e enteados há uma relação paternal/maternal muito presente, muitas vezes com responsabilidades assumidas e afeto mais fortes ou na mesma proporção se comparado em relação à filiação biológica existente. Da mesma forma, o inverso também existe e, por este motivo, o questionamento que busca ser respondido por intermédio desta pesquisa é: o reconhecimento da socioafetividade entre padrasto/madrasta e enteados é consequência da realidade fática vivenciada pelos membros da família recomposta ou há necessidade de manifestação de vontade de ambas as partes? Se reconhece a filiação socioafetiva em razão do meio em que se vive ou há parentalidade socioafetiva apenas quando há vontade por parte do padrasto/madrasta de assumirem seus enteados como filhos?

Para responder tais indagações, faz-se necessário abordar questões técnicas da socioafetividade.

\section{OS REQUISITOS PARA O RECONHECIMENTO DA SOCIOAFETIVIDADE}

Christiano Cassetari (2015, p. 29-39) dispõe acerca dos requisitos necessários para a configuração da parentalidade socioafetiva. O primeiro e indispensável requisito diz respeito (i) à existência de laços de afetividade; menciona também (ii) o tempo de convivência como outro requisito, deixando clara a impossibilidade de definir o tempo mínimo, uma vez que é impossível determinar o momento exato do nascimento da parentalidade socioafetiva; por fim, destaca (iii) a posse de estado de filho, requisito que possui regras para sua caracterização.

A afetividade, principal requisito para o reconhecimento das famílias socioafetivas, passou a compor os vínculos familiares a partir do século 21 , ao mesmo tempo em que se começou a configurar novos formatos de família, deixando de lado os encargos da Igreja, Estado, meio social e interesses institucionais e patrimoniais para buscar a realização pessoal de cada membro, a qual denomina-se eudemonismo ${ }^{6}$ (CALDERÓN, 2013, p. 207-208).

Apesar de presente há algum tempo no ordenamento jurídico, ainda há divergência doutrinária a respeito da categoria teórica ocupada pela afetividade neste meio, mas a maioria da doutrina entende a afetividade como princípio jurídico implícito nas normas do Direito de Família Brasileiro (CALDERÓN, 2013, p. 289-298).

Há possibilidade de membro de família monoparental se unir a uma pessoa que ainda não tenha constituído família anteriormente. Ou, de duas famílias monoparentais se unirem. Em ambos os casos, forma-se a família recomposta.

6 Eudemonismo, cuja tradução do grego é felicidade, era compreendido de forma diferente pelos filósofos da Antiguidade - em uma visão mais final e autossuficiente, portanto mais individual. Já para o século 21, a compreensão de família eudemonista traz valores de cuidado, afetividade, ética e responsabilidade solidária de seus membros (ALBUQUERQUE, 2011, p. 88). 
Paulo Lôbo (2019) é um dos juristas que reconhece a afetividade como princípio, entendendo sua força normativa e possibilidade de consequências em caso de descumprimento. Ainda, traz importante contribuição ao diferenciar afeto como sentimento/fato psicológico e a afetividade conferida ao estudo jurídico:

[...] a afetividade, sob o ponto de vista jurídico, não se confunde com o afeto, como fato psicológico ou anímico, este de ocorrência real necessária. O direito, todavia, converteu a afetividade em princípio jurídico, que tem força normativa, impondo dever e obrigação aos membros da família, ainda que na realidade existencial entre eles tenha desaparecido o afeto. Assim, pode haver desafeto entre pai e filho, mas o direito impõe o dever de afetividade. [...] A afetividade é o princípio jurídico que peculiariza, no âmbito da família, o princípio da solidariedade. [...] A afetividade estado psíquico global, relacionada a estado de ânimo, sentimentos e emoções é muito abrangente e por isso não está presente quando se trata de direito, já que este preocupa-se apenas com os fatos que devem receber a incidência da norma jurídica (LÔBO, 2019, p. 646-647).

O referido autor vai além e diferencia a afetividade entre pais e filhos e a afetividade entre companheiros/cônjuges; segundo ele, o dever jurídico da afetividade entre pais e filhos extingue-se tão somente com o falecimento de um deles ou com a perda do poder familiar; já a afetividade entre companheiros está presente como pressuposto de convivência.

Ricardo Calderón traz-nos a ideia de "dupla face do princípio da afetividade". Uma, chamada "face de dever jurídico", relacionada a um vínculo familiar já existente (parental, conjugal). Nesta, haveria uma imposição de dever jurídico em razão do princípio; e a outra, denominada "face geradora de vínculo familiar", que necessita de verificação fática entre as relações (parentais ou conjugais), a fim de caracterizar ou não um liame jurídico. Nessa verificação está a posse de estado de filho, requisito para o reconhecimento da socioafetividade (CALDERÓN, 2013, p. 309-310).

Há posse de estado de filho quando presentes as seguintes características: publicidade, continuidade e ausência de equívoco. A publicidade e continuidade correspondem à visibilidade e notoriedade de pai/mãe e filho socialmente e de modo contínuo. Quanto à ausência de equívoco, significa que esses fatos não podem apresentar dúvida ou ambiguidade, uma vez que a finalidade da posse de estado de filho é trazer ao mundo jurídico a verdade social (FACHIN, 1992 , p. 157).

Orlando Gomes (2002) descreve a posse de estado de filho como um conjunto de circunstâncias em que são possíveis de demonstrar a condição de filho legítimo do casal que o cria e educa, considerando dentre os requisitos para tal finalidade: o filho ter levado o nome presumido dos genitores, ter recebido tratamento contínuo de filho legítimo, ter sido reconhecido perante a sociedade e pelos próprios pais como filho legítimo.

Neste mesmo sentido, Pontes de Miranda (2012) caracteriza a posse de estado de filho pela presença dos requisitos: Nomem, Tractatus e Fama. Nomem significa a utilização do nome da pessoa que Ihe atribui a paternidade pelo filho; Tractatus corresponde ao tratamento como filho legítimo, considerando educação, saúde e meios de subsistência e, por fim, a Fama, que seria a visibilidade social de filho.

Por fim, o tempo de convivência é outro requisito analisado para reconhecimento da socioafetividade. Destaca-se, entretanto, a inexistência de qualquer regulamentação ou exigência de tempo mínimo, uma vez que a análise dos laços de afetividade e da posse de estado de filho são requisitos bem específicos e que, se atendidos, ainda que o tempo de convivência seja pequeno, a socioafetividade será reconhecida. Além disso, o tempo de convivência é pressuposto para o estabelecimento dos laços de afetividade e para a constatação da posse de estado de filho, de modo que, ausente este requisito, automaticamente não estarão presentes os demais.

\section{AUTONOMIA PRIVADA PARA O RECONHECIMENTO DA SOCIOAFETIVIDADE NAS FAMÍLIAS RECOMPOSTAS}

A noção de autonomia privada originou-se no Direito Contratual, mas passou a ser abordada também nas relações familiares em virtude da reforma e expansão do Direito Privado (MADALENO, 2012, p. 10).

A partir de então, há vários posicionamentos sobre o exercício da autonomia privada e as imposições do Estado em relação à formação e organização das famílias. Sobre este tema, Carlos Eduardo Pianovski Ruzyk (2011, p. 272) indica que quanto mais o Estado intervém nas relações familiares, mais significativos são os indícios de uma inversão de valores. Segundo ele, há necessidade de potencialização da autonomia privada a fim de atender aos princípios constitucionais da dignidade da pessoa humana e da liberdade. 
No mesmo sentido, Marcos Alves da Silva critica o modelo de família imposto pelo Estado, pois "é arquétipo das codificações oitocentistas com pretensão de regular cada quadrante por mais íntimo que fosse da vida privada" (SILVA, 2013, p. 307).

Ademais, há que se atentar para que os conceitos não sejam distorcidos, especialmente quanto à liberdade e à autonomia privada nas relações familiares:

Também não se pode concluir que a função centrada na liberdade não pretende reduzir a família a um exercício individualista de autonomia privada. Não se trata, pois, de uma tentativa de recondução a um conceito contratualista de família, mas, sim, de uma liberdade que se manifesta e se constrói no viver - e não, simplesmente, na gênese formal de um modelo unitário de família por meio da categoria abstrata do negócio jurídico (RUZYK, 2011, p. 318).

Quando há restrição ou ausência de escolhas, não há apenas um enfraquecimento da autonomia privada, mas um déficit de liberdade e, por sua vez, de autodeterminação (RUZYK, 2011, p. 272). Neste sentido, percebe-se que nas famílias recompostas há o exercício de autonomia privada no que se refere à escolha conjugal.

Quanto à autonomia presente na parentalidade socioafetiva, há necessidade de análise de algumas hipóteses: (i) a simples convivência de padrastos ou madrastas com os enteados, por si só, pode configurar a socioafetividade; (ii) é necessária a manifestação de vontade de ser pai/mãe socioafetivo(a) dos enteados; (iii) a manifestação de vontade de reconhecimento de uma parentalidade socioafetiva é automática e está presente na escolha conjugal por um par que possui filhos de relacionamento anterior, isto é, quando se escolheu o parceiro automaticamente reconheceu-se a socioafetividade. Essas hipóteses serão trabalhadas a fim de eleger uma ao final deste estudo.

Conforme já mencionado, os requisitos para o reconhecimento da socioafetividade são: os laços de afetividade, o tempo de convivência e a posse de estado de filho, ou seja, não há expressamente entre os doutrinadores o entendimento pela necessidade da autonomia privada como um dos requisitos, que seria a anuência de pais e/ou filhos socioafetivos para referido reconhecimento.

Apesar disso, os Provimentos 63/2017 e 83/2019, ambos do CNJ, que tratam do reconhecimento voluntário da parentalidade socioafetiva, trazem expressamente a disposição de que o filho menor de 18 anos (previsão do Provimento 63/2017) e acima de 12 (previsão do Provimento 83/2019) precisa manifestar sua concordância pelo reconhecimento da parentalidade socioafetiva, dispositivo este que nos faz refletir a respeito da autonomia privada do filho maior de 12 anos em aceitar seu padrasto ou madrasta como seu pai ou sua mãe socioafetivo(a).

Nas famílias recompostas, tem-se a presença de um pai ou mãe e um padrasto ou madrasta residindo no mesmo lar. Cada família, todavia, apresenta uma dinâmica e organização diferentes, pois existem famílias em que o pai ou mãe, apesar de não residirem com a criança, desempenham muito bem todos os papéis decorrentes de sua responsabilidade parental, e, dentre eles, a afetividade. De outro lado, existem relacionamentos em que o pai ou mãe que não residem com o filho arcam tão somente com a obrigação alimentícia - sem que haja convivência -, ou, em casos ainda mais extremos, sequer prestam assistência material mínima à prole.

Esses diferentes contextos familiares dentro das famílias recompostas precisam ser analisados para compreender se a socioafetividade pode ser reconhecida tão somente pelo cumprimento de requisitos fáticos que Ihe são impostos, ou se há necessidade do exercício da autonomia privada do pai ou mãe e do(a) filho(a) socioafetivo(a).

Nesse sentido, há autores que analisam o elemento vontade presente na escolha de ser pai ou mãe, e a conclusão vai ao encontro do estudo de João Baptista Villela (1979) sobre a desbiologização da paternidade:

[...] é preciso querer ser pai, o que se revelará na conduta contínua de desvelo resumida num cuidar sem limites. Só assim se estará apto a exercer o imprescindível afeto, marca necessária em uma relação familiar. Por isso mesmo quando esse elemento falta na filiação biológica e o pai se ausenta da vida do filho deve sobrelevar a paternidade socioafetiva. Assim se dá na adoção, na inseminação heteróloga e na paternidade socioafetiva. [...] E compartilhando da assertiva repetida tantas vezes pelos estudiosos da matéria, salientamos a diferença enorme que há entre quem gera - o genitor - e aquele que cria, educa e ama - o pai; genitor não é o mesmo que ser pai ou mãe. [...] (GRAMSTRUP; QUEIROZ, 2016). 
Segundo João Baptista Villela (1979, p. 414), é possível obrigar alguém a responder com seu patrimônio por sua conduta ou descumprimento de uma obrigação, mas não é possível obrigar alguém a assumir uma paternidade indesejada sem violentar a própria ideia de paternidade.

Tem tanto esta de autodoação, de gratuidade, de engajamento íntimo, que não é susceptível de imposição coativa. Pai e mãe ou se é por decisão pessoal e livre, ou simplesmente não se é. Assim, a lei e a Justiça desrespeitam gravemente uma criança quando lhe dão por pai quem, em ação de investigação de paternidade, resiste a tal condição. [...] Todo o direito de família tende a se organizar, de resto, sob o princípio basilar da liberdade, tão certo é que as prestações familiais, seja entre cônjuges, seja entre pais e filhos só proporcionam plena satisfação quando gratuitamente assumidas e realizadas (VILLELA, 1979, p. 414).

Há quem entenda que padrasto e madrasta são "estranhos jurídicos", independentemente de sua presença nas famílias recompostas. Este entendimento, juntamente com a resistência de criação de termos específicos para representar esses papeis, possui vinculação direta à criticada família nuclear e sua idealização como família padrão, considerando (equivocadamente) todos os outros modelos inferiores. Diferente de outros países, não há em nossa legislação qualquer regulamentação de direitos ou deveres de padrastos ou madrastas em relação aos seus enteados (SARAIVA; LEVY; MAGALHÃES, 2014, p. 83, 85).

Em ratificação ao argumento da inexistência de famílias com importância maior que outras, há um precioso ensinamento de Villela (1979) sobre a impossibilidade de classificar a paternidade em modelos superiores ou inferiores, em que pese seu enfoque dizer respeito à paternidade adotiva, há semelhança com a paternidade socioafetiva:

A paternidade adotiva não é uma paternidade de segunda classe. Ao contrário: suplanta, em origem, a de procedência biológica pelo seu maior teor de autodeterminação [...] Somente ao pai adotivo é dada a faculdade de um dia poder repetir aos seus filhos o que CRISTO disse aos seus apóstolos: "Não fostes vós que me escoIhestes, mas fui eu que vos escolhi a vós". Suprema expressão da autonomia paterna, que liberta, gratifica e faz crescer quem a pode manifestar e quem a pode ouvir (p. 416).

Na parentalidade adotiva há, evidentemente, uma escolha, uma vez que o exercício da autonomia privada pelos pais é muito claro, posto que realizam o cadastro de adoção e passam pelos procedimentos necessários para, efetivamente, tornarem-se pais. A parentalidade socioafetiva, muitas vezes, não se apresenta como uma escolha tão óbvia, especialmente quando oriunda de uma família recomposta, em razão de uma segunda união que trouxe filhos biológicos de relacionamentos anteriores.

Apesar de cada família recomposta ter sua história e seus membros exercerem diferentes papéis de diversas formas e funções possíveis, há duas lógicas a respeito da relação padrasto/madrasta e enteados: a substituição e a perenidade (SARAIVA; LEVY; MAGALHÃES, 2014, p. 85-86). A compreensão dessas duas lógicas é crucial para a construção das ideias conclusivas deste estudo.

A substituição normalmente ocorre em casos de divórcio, em que o pai ou a mãe que não permanecem residindo com os filhos, com eles não mantém contato, ou em caso de falecimento de um dos pais e nova formação da família pelo sobrevivente. Neste caso, o padrasto ou madrasta passa a substituir efetivamente o papel de um dos pais, ou seja, passa a figurar como pai ou mãe do filho de seu cônjuge ou companheiro(a). Já a perenidade seria o inverso; trata-se de adição, isto é, não se exclui o pai ou mãe que deixaram de residir com o filho. As responsabilidades, contato e laços de afeto permanecem com ambos os pais e podem existir também com o padrasto ou madrasta, mas neste caso é mais difícil para estes conseguirem compreender e exercer seu papel dentro da família recomposta (SARAIVA; LEVY; MAGALHÃES, 2014, p. 85-86).

Há, ainda, no entendimento dos autores do texto Quel est le rôle du beau-père en famille recomposée? Point de vue de beaux-pères, de mères et de pères (qual é o papel do padrasto na família recomposta? Ponto de vista dos padrastos, mães e pais), a existência de três papéis: o pai substituto e o pai adicional, já mencio- 
nados anteriormente, e a terceira figura que seria do "falso pai", 7 que se trata do padrasto que não assume qualquer função e não possui legitimidade perante o enteado, apenas está presente na família como cônjuge da mãe (PARENT; FORTIN, 2008 apud SARAIVA; LEVY; MAGALHÃES, 2014, p. 85, 86).

Pesquisas demonstram que quanto menor a idade do filho maior a facilidade em relacionar-se de forma saudável com seu padrasto ou madrasta. Assim, a partir dos seis anos de idade da criança, aumenta a dificuldade em se estabelecer essa relação, especialmente quando há contato e vínculo com o pai ou mãe que não reside em conjunto. Já nos casos em que os pais apoiam a relação do filho com o padrasto ou madrasta, é mais fácil que aquele esteja disposto a manter um bom relacionamento com esses. Da mesma forma, quando os filhos perdem o contato com um dos pais, há maior facilidade no estabelecimento de laços afetivos com o padrasto ou madrasta (SARAIVA; LEVY; MAGALHÃES, 2014, p. 85-86).

A fim de possibilitar um bom relacionamento entre os membros das famílias recompostas, parece necessário que sejam estabelecidos espaços, papéis e funções de cada um dos membros. Tal definição prévia evita conflitos, uma vez que é visível que a liberdade dos membros terá interferência em razão das novas pessoas que passam a fazer parte da família. Assim, a existência de um conjunto próprio de regras de convivência a serem observadas pelos membros pode ajudar na convivência harmoniosa da nova família em formação (TEIXEIRA, 2005, p. 120).

Segundo João Baptista Villela, a parentalidade (independente de qual seja a origem ou nomenclatura desta filiação) é uma questão de escolha. Já em 1979 o autor argumentava sobre a possibilidade de escolher evitar a gravidez tanto quanto a possibilidade de gerar um filho por meio de inseminações artificiais. Na sua visão, essas possibilidades trazem cada vez mais autonomia para o exercício da parentalidade.

Chegados à plenitude desse novo estágio, os filhos, mais do que nunca, serão experimentados não como salário do sexo, mas como o complemento livremente buscado e assumido de um empenho de personalização, que lança suas raízes no mais poderoso dinamismo transformacional do homem, que é o dom de si mesmo (VILLELA, 1979, p. 413).

Por sua vez, ressalta-se o grande avanço jurídico quanto ao reconhecimento da filiação socioafetiva e a possibilidade de realização de maneira voluntária, mediante requerimento ao oficial registrador, nos termos do Provimento 63/2017 e 83/2019 do CNJ.

No requerimento voluntário de parentalidade socioafetiva há evidente manifestação da vontade e, por sua vez, exercício da autonomia privada daquele que invoca os termos do Provimento e declara ser pai ou mãe socioafetivo de determinada pessoa perante o registrador. As consequências jurídicas que serão aplicadas a partir deste reconhecimento são as mesmas de uma filiação biológica, de modo que a inclusão do nome do pai ou mãe socioafetivos no registro civil do filho apenas confirmará a posse de estado de filho e o cumprimento dos demais requisitos.

Conforme mencionado, no reconhecimento voluntário da parentalidade socioafetiva de filho maior de 12 anos (artigo 10, do Provimento 83/2019 - CNJ), há o exercício da autonomia privada tanto do pai/mãe afetivos quanto do filho que, obrigatoriamente, precisa manifestar sua anuência nos termos do artigo 11 , § 4으, do Provimento 83/2019 CNJ: "Se o filho for menor de 18 anos, o reconhecimento da paternidade ou maternidade socioafetiva exigirá o seu consentimento". Não há dúvidas, portanto, da existência da autonomia privada no reconhecimento voluntário de parentalidade socioafetiva.

Mesmo quando o reconhecimento da socioafetividade não é voluntário, entende-se que ainda assim há a manifestação de vontade, uma vez que, para a configuração dos requisitos necessários ao reconhecimento, tanto os laços afetivos quanto a posse de estado de filho dependem de escolhas, interesse e responsabilidades parentais.

Retomando o precedente de relatoria da ministra Nancy Andrighi, há trecho em seu voto que demonstra o entendimento da manifestação de vontade no vínculo da filiação socioafetiva:

\footnotetext{
Neste caso, quando os autores mencionam "pai", estende-se neste estudo a aplicação à mãe também, uma vez que hoje ambos os sexos assumem a guarda unilateral ou ainda são os guardiões dos filhos em casos de fixação de guarda compartilhada, de modo que, neste estudo, não há distinção de gênero ao tratar do tema.
} 
Por isso, se a existência da filiação sócio-afetiva é trazida ao mundo jurídico por declaração de vontades, cumpre ao julgador reconhecer validade e eficácia nesse ato (STF Resp 878.941/DF, 2007).

Fora demonstrado anteriormente que existe, em muitas famílias recompostas, a figura do padrasto ou madrasta assumindo tão somente funções e papéis conjugais na família, de apoio à sua companheira ou companheiro, ainda que resida no mesmo lar que os enteados. Isto é, em certos casos, não há o cumprimento dos requisitos da posse de estado de filho e dos laços afetivos, o que indica a não observância dos requisitos mínimos para o reconhecimento da socioafetividade. Da mesma forma, foi mencionado que, normalmente, quando os filhos têm contato com o pai ou mãe que não reside na mesma casa e quando são maiores de seis anos, dificilmente criam laços parentais com os padrastos ou madrastas, o que pode levar ao não cumprimento dos requisitos necessários para a filiação socioafetiva.

Por isso, entende-se que para o reconhecimento não voluntário da parentalidade socioafetiva deverão ser observados os requisitos estipulados para o seu reconhecimento juntamente com a autonomia privada que, apesar de não constar expressamente como um dos requisitos, está implicitamente vinculada aos requisitos da posse de estado de filho e da existência de laços afetivos, uma vez que "pai e mãe ou se é por decisão pessoal e livre, ou simplesmente não se é" (VILLELA, 1979, p. 414).

\section{CONSIDERAÇÕES FINAIS}

Com base no estudo realizado, é considerada família recomposta aquela em que estão presentes filhos de relacionamentos anteriores em novo relacionamento afetivo, passando a conviverem padrasto ou madrasta, um dos pais e os filhos ou enteados, todos no mesmo lar. Esta convivência entre padrasto ou madrasta e enteados pode ser reconhecida como socioafetividade, desde que presentes os requisitos necessários para tal, quais sejam: laços de afetividade, tempo de convivência e posse de estado de filho. Do mesmo modo, foi possível compreender o papel da autonomia privada nas relações familiares e a sua aplicação no reconhecimento da parentalidade socioafetiva.

Em cumprimento ao método hipotético-dedutivo utilizado na presente pesquisa, as hipóteses levantadas para problematização deste estudo foram: (i) a simples convivência de padrastos ou madrastas com os enteados, por si só, pode configurar socioafetividade; (ii) é necessária a manifestação de vontade por parte do padrasto/madrasta de ser pai/mãe socioafetivo dos enteados; (iii) a manifestação de vontade de reconhecimento de uma parentalidade socioafetiva é automática e está presente por meio da escolha conjugal por um par que possui filhos de relacionamento anterior, pois, quando se escolheu o(a) parceiro(a), automaticamente fora reconhecida a socioafetividade.

A terceira hipótese parece ser a mais incongruente e, desde logo, deve ser descartada. Conforme já mencionado, o estudo trouxe a caracterização de três papéis exercidos por padrastos ou madrastas: pai/mãe substituto, pai/mãe adicional e "falso pai/mãe", sendo os primeiros aqueles padrastos ou madrastas que substituem os pais e assumem as responsabilidades parentais, os segundos aqueles que somam e o vínculo permanece com o pai ou mãe em conjunto com o padrasto ou madrasta, e o terceiro, denominado "falso pai" (que, no nosso entendimento, também pode ser "falsa mãe"), que seria o padrasto ou madrasta preocupados tão somente com sua relação conjugal e com funções que se limitam a esta relação, não assumindo quaisquer responsabilidades perante seus enteados.

Entende-se que a simples aceitação de entrar em um relacionamento com uma pessoa que já tem filhos de relacionamentos anteriores não faz do padrasto ou madrasta pai ou mãe socioafetivo(a), pois a autonomia privada foi manifestada unicamente em relação ao casamento ou constituição de união estável, não sendo possível estender automaticamente a anuência para a caracterização do vínculo com o(a) companheiro(a) ao relacionamento com os enteados e nem mesmo afirmar que essa escolha foi conjunta. Por este motivo, a hipótese foi considerada falsa.

As duas hipóteses remanescentes são propriamente o objeto de questionamento presente no título deste artigo: Seria a socioafetividade, dentro das famílias recompostas, passível de ser reconhecida pela simples situação fática ou há necessidade de manifestação da autonomia privada para escolher entre exercer ou não essa parentalidade socioafetiva? 


\section{Debate}

Para fundamentar a resposta é necessária a aplicação dos requisitos da socioafetividade abordados anteriormente. O tempo de convivência certamente será requisito cumprido por boa parte das famílias recompostas, porém os requisitos (i) laços de afetividade e (ii) posse de estado de filho deverão ser observados cautelosamente, uma vez que não podem ser considerados presentes, de modo geral, em todas as famílias recompostas.

O termo afetividade, do ponto de vista jurídico, não corresponde ao afeto psicológico e emocional, mas está vinculado às responsabilidades, cuidado e funções assumidas na relação parental-filial. Por sua vez, para configurar a posse de estado de filho é imprescindível a presença de critérios como publicidade, continuidade e ausência de equívoco, ou ainda, Nomem, Tractatus e Fama; como mencionado anteriormente. Nem todos os padrastos e madrastas, no entanto, assumem as responsabilidades e consideram o enteado como filho, tratando e chamando-o como tal; nestes casos, entende-se que os requisitos para o reconhecimento da parentalidade socioafetiva não estariam presentes. É considerada falsa, portanto, a primeira hipótese, uma vez que a convivência, por si só, não configura a socioafetividade.

Com relação à autonomia privada, objeto da segunda hipótese, esta encontra-se claramente demonstrada no reconhecimento voluntário da socioafetividade, disposto no Provimento 63/2017, alterado pelo Provimento $83 / 2019$, ambos do CNJ, em que há previsão de expressa manifestação de vontade pelo pai ou mãe socioafetivos e pelo filho menor de 18 e maior de 12 anos.

Sabe-se que o exercício da autonomia privada está presente a todo momento nas famílias recompostas, nas mais diversas escolhas feitas por essas. No que se refere ao reconhecimento da posse de estado de filho, os envolvidos diretamente na relação (leia-se enteados e padrastos ou madrastas) devem manifestar vontade específica. Isto significa que tanto o padrasto quanto a madrasta devem dirigir a sua vontade no sentido do reconhecimento do enteado como filho, como também o enteado reconhecer padrasto ou madrasta como pai ou mãe (reconhecimento recíproco). Esse reconhecimento precisa ser exteriorizado, ou seja, deve haver reconhecimento social (Nomem, Tractatus e Fama), não bastando apenas seu reconhecimento no seio da família recomposta.

Assim sendo, antes de qualquer análise do ponto de vista jurídico, há necessidade de verificação da convivência da família, isto é, em algum momento do relacionamento dessa família houve o exercício da autonomia privada por seus membros, seja para aceitar ou rejeitar (por meio de palavras ou ações) o tratamento, a responsabilidade, o nome, entre outros aspectos que remetem à existência de socioafetividade. Não pode haver a presunção de que o mero convívio pressupõe a socioafetividade; ao contrário, a presunção é de que não há parentalidade socioafetiva, por isso se exige a manifestação expressa de vontade e reciprocidade que configure a posse de estado de filho para seu reconhecimento.

Conclui-se, então, que a segunda hipótese se apresenta como a mais acertada para responder à indagação do presente estudo, constatando-se que a autonomia privada faz-se necessária ao reconhecimento da socioafetividade, seja no que diz respeito à formação dos laços de afetividade ou na configuração da posse de estado de filho, de modo que a autonomia privada refletirá a situação fática de existência ou não de socioafetividade.

\section{REFERÊNCIAS}

ALBUQUERQUE, Fabíola Santos. A família eudemonista do século XXI. CONGRESSO BRASILEIRO DE DIREITO DE FAMÍLIA, 8., 2011. Anais [...]. IBDFAM, 2011. p. 88-95. Disponível em: http://www.ibdfam.org.br/assets/upload/anais/269.pdf. Acesso em: 19 maio 2019.

CALDERÓN, Ricardo Lucas. Princípio da afetividade no direito de família. Rio de Janeiro: Renovar, 2013. 438 p.

CASSETARI, Christiano. Multiparentalidade e parentalidade socioafetiva. 2. ed. São Paulo: Atlas, 2015. 247 p.

CONSELHO NACIONAL DE JUSTIÇA. Provimento 63 de 14 de novembro de 2017. Disponível em: http://www.cnj.jus.br/files/ atos_administrativos/provimento-n63-14-11-2017-corregedoria.pdf. Acesso em: 12 fev. 2019.

DIAS, Maria Berenice. Sociedade de afeto: um nome para a família. Revista Brasileira de Direito de Família, Porto Alegre: Síntese, v. I, n. 1, p. 34, abr./jun. 1999.

FACHIN, Luiz Edson. Estabelecimento da filiação e paternidade presumida. Porto Alegre: Sergio Antonio Fabris, 1992.183 p. GOMES, Orlando. Direito de família. 4. ed. Rio de Janeiro: Forense, 2002. 474 p. 
GRAMSTRUP, Erik Frederico; QUEIROZ, Odete Novais Carneiro. A socioafetividade e a multiparentalidade. Revista Nacional de Direito de Família e Sucessões, Porto Alegre, v. 2, n. 11, p. 104-127, mar./abr. 2016.

LÔBO, Paulo Luiz Netto. Paternidade socioafetiva e o retrocesso da Súmula 301-STJ. Anais [...]. IBDFAM. Disponível em: http:// www.ibdfam.org.br/_img/congressos/anais/37.pdf. Acesso em: 12 fev. 2019.

MADALENO, Rolf. A crise conjugal e o colapso dos atuais modelos de regime de bens. Revista Brasileira de Direito das Famílias e Sucessões, Porto Alegre, v. 25, p. 5-31, dez./jan. 2012.

MACCORMICK, Neil. Retórica e o Estado de Direito. São Paulo: Elsevier, 2008. 389 p.

PARENT, C.; FORTIN, M. Quel est le rôle du beau-père en famille recomposée? Point de vue de beaux-pères, de mères et de pères [on-line]. 2008. Disponível em: http://www.dossierfamilial.com/famille/droit-demarche/quels-droits-pour-le-beauparent. In: SARAIVA, Camille de Andrade; LEVY, Lídia Levy; MAGALHÃES, Andrea Seixas. O lugar do padrasto em famílias recompostas. Barbarói, Santa Cruz do Sul, n. 41, p. 82-99, jul./dez. 2014.

PERLINGIERI, Pietro. Perfis do Direito Civil. 3. ed. Trad. Maria Cristina de Cicco. Rio de Janeiro: Renovar, 2007. 359 p.

PONTES DE MIRANDA, Francisco Cavalcanti. Tratado de direito privado: Parte Especial. Tomo IX: Direito de família. Direito parental. Direito protectivo. São Paulo: Revista dos Tribunais, 2012. 623 p.

PUGLIESE, William Soares. Princípios da jurisprudência. Belo Horizonte: Arraes Editores, 2017. 172 p.

RUZYK, Carlos Eduardo Pianovski. Institutos fundamentais do Direito Civil e liberdade(s): repensando a dimensão funcional do contrato, da propriedade e da família. Rio de Janeiro: GZ Ed., 2011. p. 272.

SARAIVA, Camille de Andrade; LEVY, Lídia Levy; MAGALHÃES, Andrea Seixas. O lugar do padrasto em famílias recompostas. Barbarói, Santa Cruz do Sul, n. 41, p. 82-99, jul./dez. 2014.

SILVA, Marcos Alves da. Da Monogamia: a sua superação como princípio estruturante do direito de família. Curitiba: Juruá, 2013.

SUPERIOR TRIBUNAL DE JUSTIÇA. RESP 878.941/DF. Relatoria min. Nancy Andrighi. Julgamento: 17/9/2007. Disponível em: https://ww2.stj.jus.br/processo/revista/documento/mediado/?componente=ATC\&sequencial=3318049\&num_registro $=200600862840 \&$ data $=20070917 \&$ tipo $=51 \&$ formato=PDF. Acesso em: 28 nov. 2019.

SUPREMO TRIBUNAL FEDERAL. ADI 4277/DF. Relatoria min. Luiz Fux. Julgamento: 14/10/2011. Disponível em: http://portal.stf. jus.br/processos/detalhe.asp?incidente=2598238. Acesso em: 22 nov. 2019.

SUPREMO TRIBUNAL FEDERAL. ADPF 132/RJ, Relatoria Min. Ayres Britto. Julgamento: 14/10/2011. Disponível em: http://portal.stf.jus.br/processos/detalhe.asp?incidente=2598238. Acesso em: 22 nov. 2019.

SUPREMO TRIBUNAL FEDERAL. RE 898060, Relatoria Luiz Fux. Julgamento: 21/9/16. Disponível em: http://www.stf.jus.br/arquivo/cms/noticianoticiastf/anexo/re898060.pdf. Acesso em: 12 fev. 2019.

TEIXEIRA, Ana Carolina Brochado. Familia, guarda e autoridade parental. Rio de Janeiro: Renovar, 2005. p. 120.

VALADARES, Maria Goreth Macedo. Famílias recompostas. CONGRESSO BRASILEIRO DE DIREITO DE FAMÍLIA, 5., 2005. Anais [...]. IBDFAM, 2005. Disponível em: http://www.ibdfam.org.br/_img/congressos/anais/50.pdf. Acesso em: 12 fev. 2019.

VILLELA, João Baptista. Desbiologização da paternidade. Revista da Faculdade de Direito da Universidade Federal de Minas Gerais, n. 21, p. 400-418, maio 1979. 